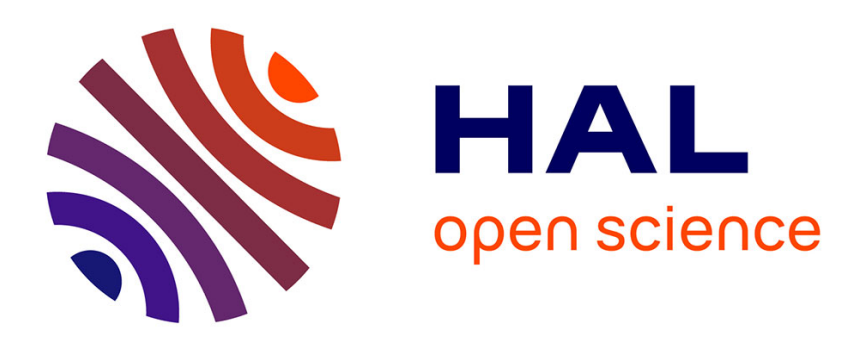

\title{
Enolization versus carbonylation at glassy carbon surface through cathodic means
}

\author{
Jacques Simonet
}

\section{To cite this version:}

Jacques Simonet. Enolization versus carbonylation at glassy carbon surface through cathodic means.

Electrochemistry Communications, 2013, 31, pp.1-4. 10.1016/j.elecom.2013.02.016 . hal-00915150

\author{
HAL Id: hal-00915150 \\ https://hal.science/hal-00915150
}

Submitted on 6 Dec 2013

HAL is a multi-disciplinary open access archive for the deposit and dissemination of scientific research documents, whether they are published or not. The documents may come from teaching and research institutions in France or abroad, or from public or private research centers.
L'archive ouverte pluridisciplinaire HAL, est destinée au dépôt et à la diffusion de documents scientifiques de niveau recherche, publiés ou non, émanant des établissements d'enseignement et de recherche français ou étrangers, des laboratoires publics ou privés. 


\title{
Enolization versus Carbonylation at Glassy Carbon Surface through Cathodic Means.
}

\author{
Jacques Simonet* \\ Equipe MaCSE, UMR 6226, Université de Rennes, Campus de Beaulieu, 35042 Rennes \\ Cedex, France.
}

\begin{abstract}
The cathodic reduction of $\omega$-bromomethylarylketones in aprotic organic solvents (such as propylene carbonate) containing tetraalkylammonium iodides achieved at smooth glassy carbon (GC) permits through a selective one-electron reduction, the scission of the $\mathrm{C}-\mathrm{Br}$ bond. Quite unexpectedly, the free radical thus formed is prior attached to the carbon surface in its enolic form (GC-O- $\left.(\mathrm{Ar}) \mathrm{C}=\mathrm{CH}_{2}\right)$. Successive radical addition processes may lead to a redox polymer based on the one-electron oxidation of enol ethers. The average superficial enol concentration at the carbon surface (found to be about $2.5 \times 10^{-8} \mathrm{~mol} \mathrm{~cm}^{-2}$ ) was assessed by the halogen index (iodine or bromine) via halogen addition to the double bonds followed by the micro-coulometric reduction of the resulting vicinal di-halo compounds.
\end{abstract}

Key-words: $\omega$-bromomethylarylketones; Glassy carbon; Enol radical grafting; Enolization; modified electrodes.

\section{Introduction}

The cathodic scission of carbon-halogen bonds for organic halides ( $\mathrm{RX}$ and ArX with $\mathrm{X}=\mathrm{I}$ or $\mathrm{Br}$ ) continues even nowadays to induce great interest. Many studies were undertaken on the direct and indirect $\mathrm{C}$-X bond scission processes [1,2]. At carbon electrodes, heterogeneous reduction processes correspond most generally to a hydrogenolysis via a twoelectron scission.

Conditions for realizing one-electron scissions of $\mathrm{C}-\mathrm{X}$ bonds and the concomitant formation of organic free radicals are being intensively developed. This research is driven by the interest to obtain coupling reaction and also the attachment of those radicals at solid surfaces. Activated organic halides, for instance benzyl bromide, were reported to be reduced at silver in two well-separated one-electron steps [3], and the immobilization of benzyl radicals at glassy carbon could be established [4]. Quite similarly, "allylation" and 
"propargylation" of GC using radical attachments from corresponding bromides were achieved [5]. Doping of carbon electrodes by thin deposits or nano-particles of transition metals (like $\mathrm{Pd}^{0}$ at the sub-nanomolar concentration) also permitted one-electron cleavage of 1-haloalkanes [6]. Beyond significantly activated organic substrates, free radicals grafting from neutral organic species appears quite unusual. Alternatively, a general mode of aryl radical generation has been developed by using organic cationic substrates such as functionalized aryl diazonium salts widely employed as convenient and general pathway for solid surface decoration [7].

Still in the field of surface modification, other simple and efficient grafting ways through arylation of carbons are sought for in many applications regarding sensing and catalysis. It certainly appeals for new and innovating processes: until now, most of aromatic $\pi$-donors and $\pi$-acceptors (e.g. nitroarenes) were immobilized at electrodes by the diazonium way.

Here is presently reported a simple and efficient one-electron cathodic cleavage of $\mathrm{ArCOCH}_{2} \mathrm{Br}$ in high dielectric permittivity organic solvents in the presence of a tetraalkylammonium iodide as supporting salt. A similar process has been described for the attachment of anthraquinone at carbon via one-electron reduction of 9,10-[AntQ]- $\mathrm{CH}_{2} \mathrm{Br}$ [8]. The key step of the process is the in situ conversion of $\mathrm{RBr}$ into $\mathrm{RI}\left(\mathrm{E}_{\mathrm{RBr}}<\mathrm{E}_{\mathrm{RI}}\right)$ expected to occur at the interface ( $\mathrm{I}^{-}$adsorbed). Therefore, since the global two-electron reduction of the C-I bond occurs according to two neatly separated one-electron steps, one can selectively produce $\mathrm{R}^{\bullet}$ radicals from organic bromo derivatives.

The great novelty of the present communication is the mode of attachment of the radical $\mathrm{ArCOCH}_{2}{ }^{\bullet}$ supposed first to be grafted in its keto-form. With several substituted $\omega$ bromoacetophenones, it is shown for the first time that the immobilization occurs through the enol form (Scheme 1, reactions (1) and (2)) leading to the generation of GC-O-C=C linkages. The modification, therefore, to a great extent concerns the layers of aromatic enol ethers reported to be reversibly oxidized into their radical cations. Attachment of redox polymers (poly-enols as thick multi-layer deposits) could be established. This first contribution deals especially to the cathodic immobilization of radicals issued from $\omega$-bromoacetophenones $\left(\mathrm{BrCH}_{2} \mathrm{COC}_{6} \mathrm{H}_{5} \mathrm{X}\right.$ with $\mathrm{X}=4-\mathrm{H}$ 1a, 4- $\mathrm{CH}_{3} \mathbf{1 b}, 4-\mathrm{OCH}_{3}$ 1c) together with those of bromoacetyl-2-pyrene $\mathbf{2}$ and bromoacetyl-2-naphthalene $\mathbf{3}$. 


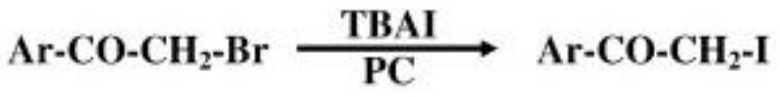

$$
\begin{aligned}
& \mathrm{Ar}-\mathrm{CO}-\mathrm{CH}_{2}-\mathrm{I} \stackrel{\mathrm{e} /-\mathrm{I}^{-}}{\longrightarrow} \mathrm{Ar}-\mathrm{CO}-\mathrm{CH}_{2}{ }^{-}
\end{aligned}
$$

$$
\mathrm{Ar}-\mathrm{CO}-\mathrm{CH}_{2}^{+}+\mathrm{e}+\mathrm{SH} \longrightarrow \mathrm{Ar}-\mathrm{CO}-\mathrm{CH}_{3}+\mathrm{S}^{-}
$$

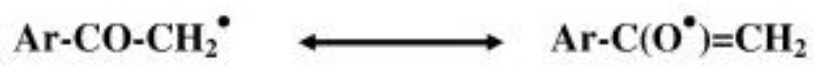

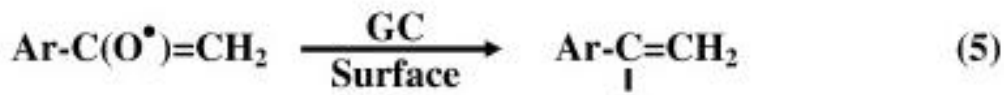
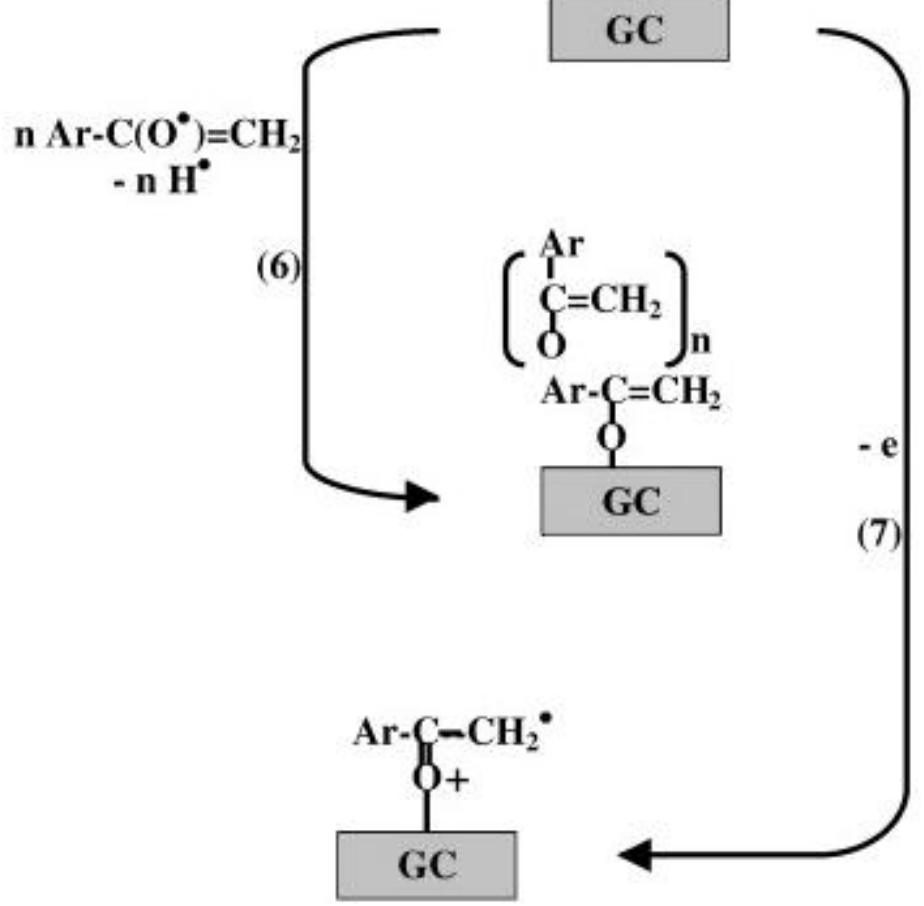

Scheme 1. Proposal for the electrochemical reactivity of the free radical issued from the C-Br cleavage of bromoketones.

\section{Experimental}

Electrolyses were essentially carried out in $0.1 \mathrm{M}$ solutions of $\mathrm{Bu}_{4} \mathrm{NI}$ (TBAI) in propylene carbonate (PC) possibly added of ethylene carbonate (EC) used then in a 50/50 (v:v) mixture since EC is solid at room temperature. Tetramethylammonium- and tetraethylammonium iodides could be employed as well. The use of more common solvents like N,Ndimethylformamide (DMF) or acetonitrile (ACN) did not give satisfactory results for 
observing the expected one-electron process. In principle, experiments described in this work did not need special treatment of electrolytic solutions. Solvents are employed as received.

Potentials are referred to the aqueous $\mathrm{Ag} / \mathrm{AgCl} / \mathrm{KCl}_{\text {(sat). }}$ The electrochemical instrumentation has been previously reported [6].

GC electrodes had an apparent surface area of $0.8 \mathrm{~mm}^{2}$ and $7 \mathrm{~mm}^{2}$ (GC). All carbon samples were purchased from Tokai Carbon Co (code: GC Rod). Prior being modified, all electrodes were carefully polished with silicon carbide paper: first with P 500 (Struers) and then with Norton polishing paper (type 02 and 03). Coulometric measurements and electrolytic deposits were performed using three-electrode cells separated with a fritted glass.

\section{Results}

\subsection{Cathodic reduction of $\omega$-bromomethylarylketones}

Bromomethylacetophenones (phenyl substituted in the 4-position) were tested electrochemically using GC as cathode material. In the conditions given in the experimental (use of a PC-EC mixture as solvent containing an iodide as a salt), the first reduction step, usually featuring a two-electron process is clearly split in two steps, I and II ( $E_{p}=-0.97$ and 1.19 V, respectively, with 1c) as depicted in Figure 1, curve A. This features a process where the first step corresponds to the generation of free aryl-acetyl radical without its fast ensuing cathodic reduction to the anion. At more negative potentials, a large reduction step III $\left(\mathrm{E}_{\mathrm{p}}=-\right.$ $2.06 \mathrm{~V}$ ) features the reduction of acetophenone (reactions 1, 2 and 3, Scheme 1). Using other cathodic materials $(\mathrm{Pd}, \mathrm{Au}$, and $\mathrm{Pt})$, the step I is clearly shifted toward less negative potentials (curve B: at gold). Figure 2 A depicts results obtained under similar conditions with 2. 


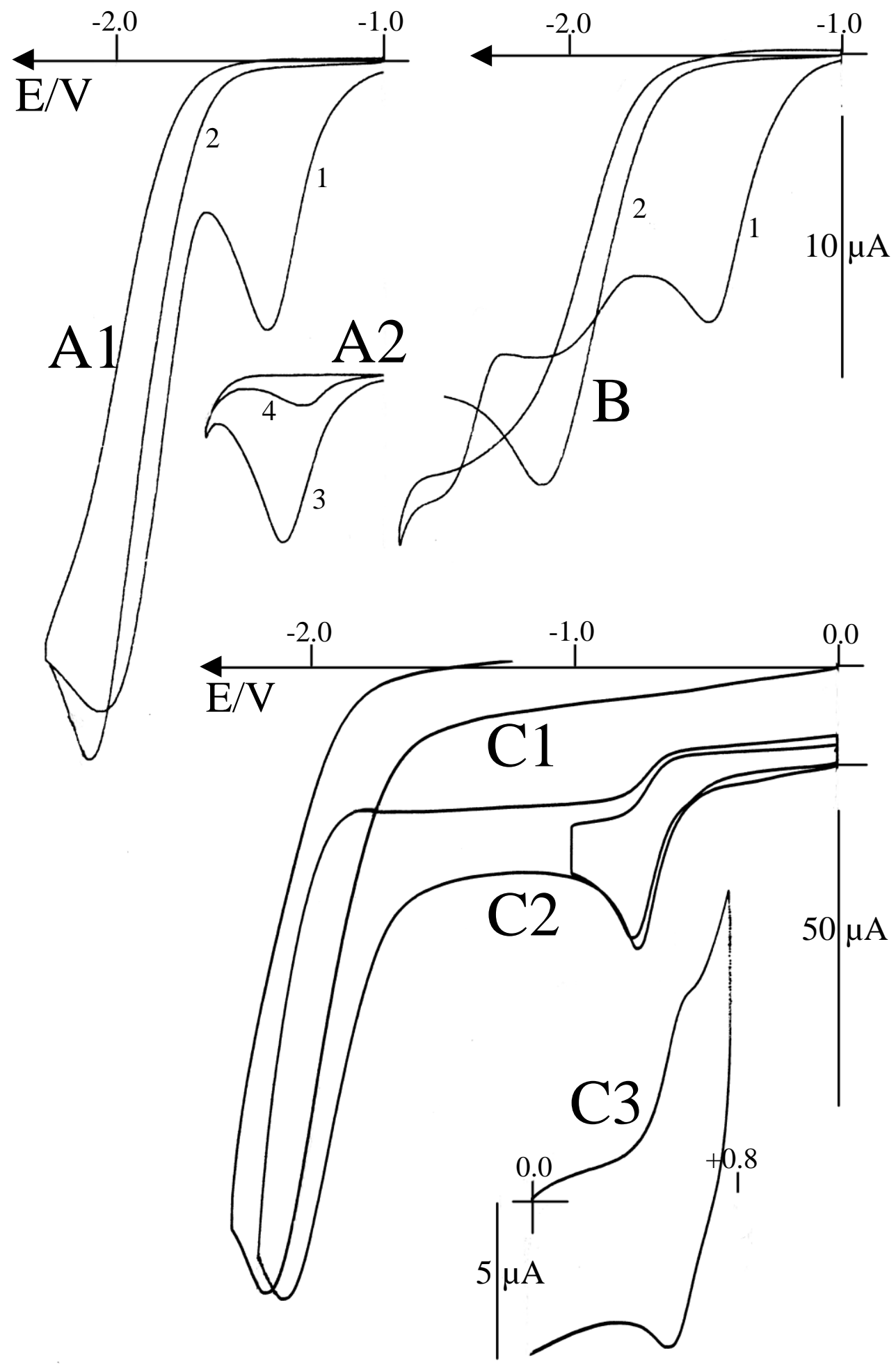

Figure 1. Voltammetry of 1c (concentration: $12.8 \mathrm{mmol} \mathrm{L}^{-1}$ ) in PC + TBAI at solid electrodes. Scan rate: $50 \mathrm{mV} \mathrm{s}^{-1}$. Electrode surface area: $0.8 \mathrm{~mm}^{2}$. A) Response at a GC electrode. B) Response at a smooth gold electrode. C) Bromination of the electrode modified at $-0.9 \mathrm{~V}$ by fixed potential electrolysis (total amount of charge: $0.8 \times 10^{-3} \mathrm{C}$ ). Two scans. In the inset, principle of the bromination process and its reduction (re-generation of the enol ether) between -0.1 and $-2.0 \mathrm{~V}$. 


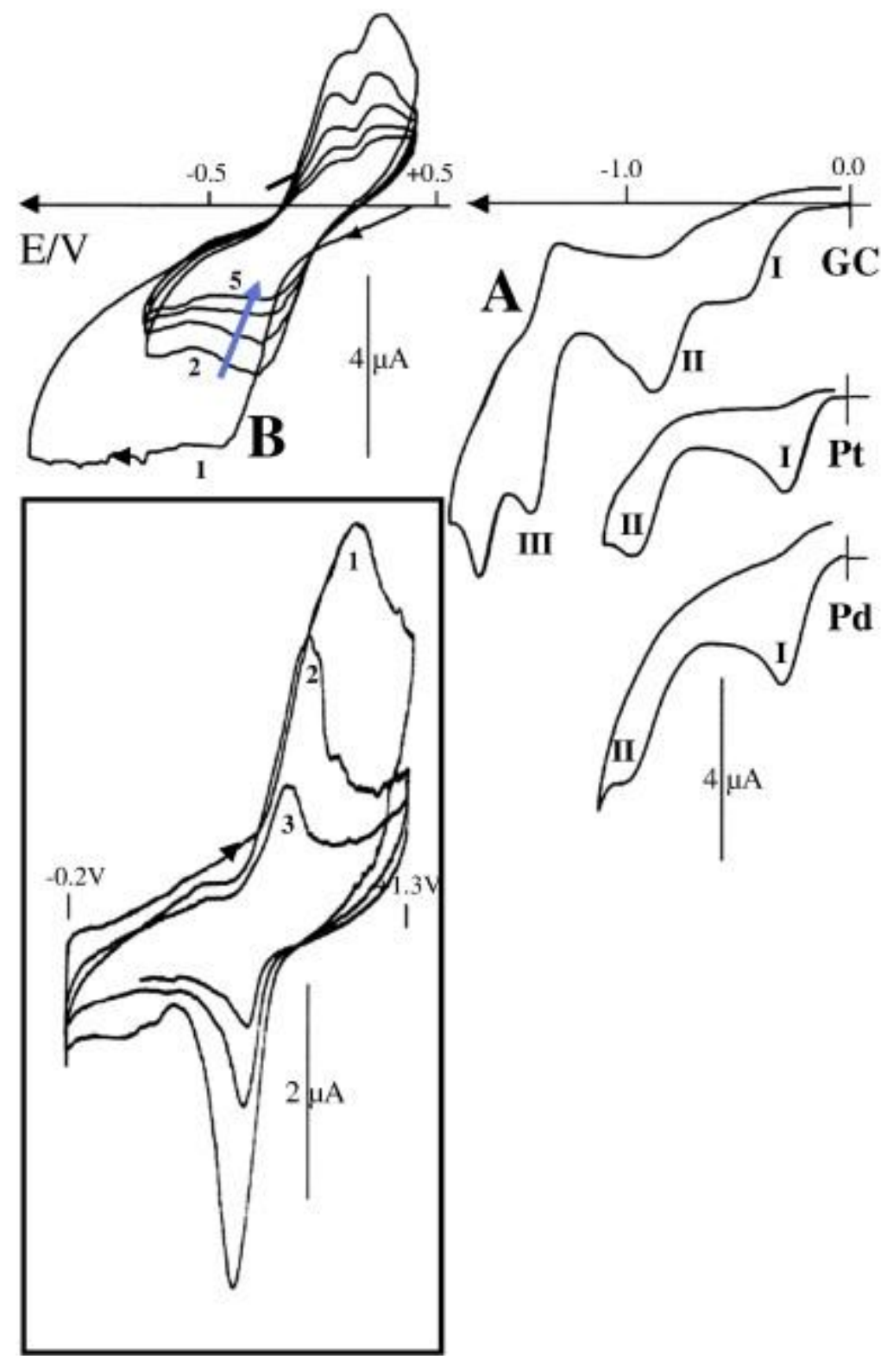

Fig 2. Voltammetries of bromomethyl-ketopyrene 2 (concentration: $3.6 \mathrm{mmol} \mathrm{L}^{-1}$ ) in PC-EC $(50: 50 \mathrm{v} / \mathrm{v})$ containing TBAI. San rate: $50 \mathrm{mV} \mathrm{s}^{-1}$. Surface area of used solid electrodes: $0.8 \mathrm{~mm}^{2}$.

A) Voltammetry at GC, Pt, and Pd electrodes. B) Initial reduction $\left(E_{R}=-0.6 \mathrm{~V}\right)$ of the deposit after bromination (scan 1) in $\mathrm{DMF} / \mathrm{TBABF}_{4}$. The regeneration of enol ether moieties (double reversible step) is followed by scans 2 to 5 .

B) For comparison, in the inset: oxidation (first three scans) of the layer obtained from $\mathbf{1 b}$.

Micro-coulometric measurements at the reduction step I were done (amounts of charge of about $0.5 \times 10^{-3} \mathrm{C} \mathrm{mm}^{-2}$ ) in order to trap free radicals at the GC surface and to test the nature of the surface modification. Quite surprisingly, we do not notice - when running the resulting electrode in a solution free of organic substrate - a large reduction peak that would 
correspond to the immobilized acetophenone. On the contrary, a reversible oxidation step at moderate oxidation potentials appears $(\mathrm{Ep}<+0.5 \mathrm{~V})$ and would suggest that the free radical is immobilized to a large extent at the GC surface under its enolic form. (Scheme 1, reaction 5). This is confirmed by FTIR spectroscopy (Figure 3, spectra A, B, and C, relative to bromomethyl-ketones 1a, 1c, and 2). As a matter of fact, large $v_{\mathrm{C}=\mathrm{O}}$ vibrations are not present while $v_{\mathrm{C}-\mathrm{O}}$ bands always appear. In order to check the indubitable presence of double bonds grafted at the GC surface, we used the classical method of bromine or iodine index simply obtained by the contact of the electrode for a few tens of seconds with a dilute solution of halogen in cyclohexane $\left(\mathrm{Br}_{2}, 3 \%\right)$ or ethanol $\left(\mathrm{I}_{2}, 5 \%\right)$, followed by the total reduction of the di-halo-form in the course of the first scan as depicted in Figure 1 (inset). The integration of the charge allows estimating the enol superficial concentration at the GC surface through the double bond. Thus, coverage values based on the double bond could be assessed. For example, using bromine (Figure 1 C), 1a, $\mathbf{1 b}$ and 1c, the coverages of $3.5,3.4$, and $1.8 \times 10^{-8} \mathrm{~mol} \mathrm{~cm}^{-2}$, respectively, were found. Employing iodine, the coverage values are significantly smaller (about 10 times) presumably owing to a slower diffusion of the halogen inside the grafted layers. 
A

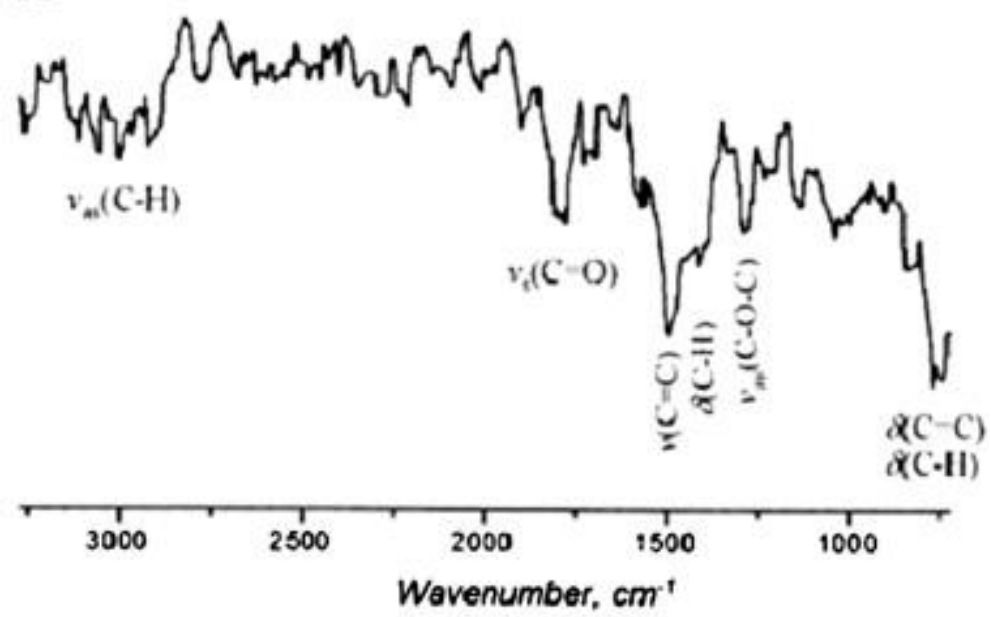

B
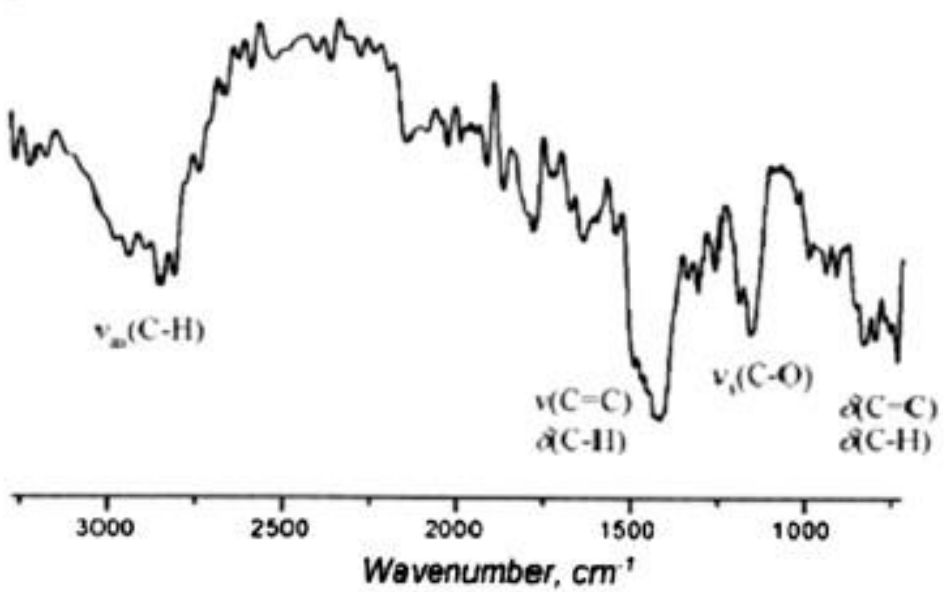

C
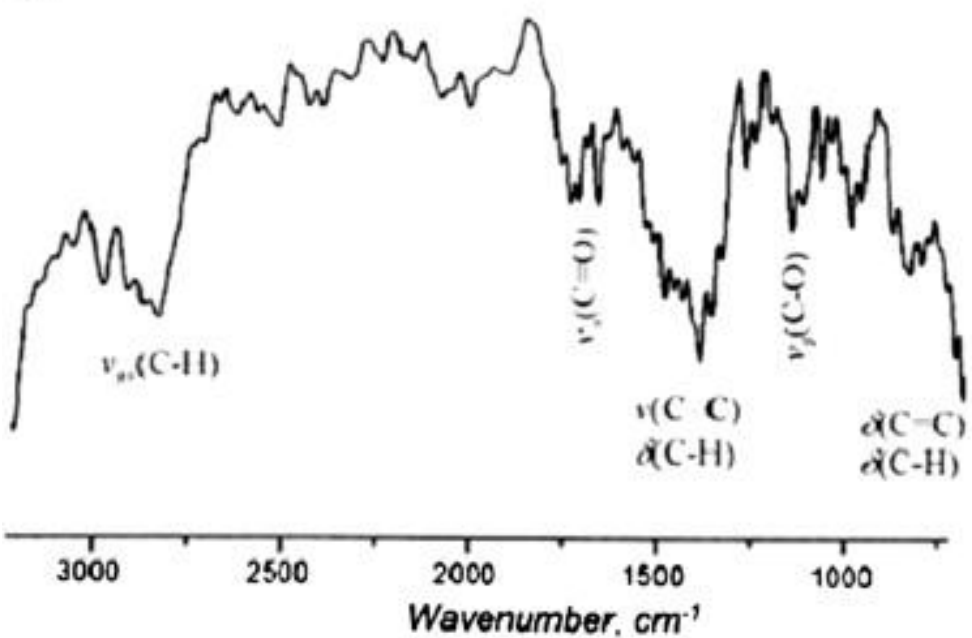

Fig. 3. FTIR spectra of different layers obtained from bromo-ketoarenes at smooth GC. A, B and $\mathrm{C}: \mathbf{3}, \mathbf{2}$, and 1a, respectively. 


\subsection{Anodic oxidation of immobilized aryl enol ethers}

Enol ethers are known to be oxidized in two steps [9] in polar organic solvents at the potentials lower than $+1 \mathrm{~V}$. First one-electron exchange is electrochemically reversible (formation of the radical cation) leading to a slow radical coupling. On the contrary, the produced di-cation was reported to react rather fast with nucleophiles (moisture) present in the liquid electrolyte. In the case of the attached to the carbon surface enol, one may also expect a reversible anodic response. This way, first oxidation step was used for estimating the coverage ratio of enolic forms into the attached layer.

Two precise examples are focused on:

a) The one-electron reduction of bromo-methylpyrene $\mathbf{2}$ (as pictured in Figure 2) permitted to obtain a deposit after an electrolysis at $-0.6 \mathrm{~V}$ with an amount of electricity of $0.35 \times 10^{-3} \mathrm{C} \mathrm{mm}^{-2}$. After rinsing with acetone, the layer is immediately allowed to react with bromine. As exhibited in Figure 2C, the bromine index estimation is complicated by the electrochemical conversion of the $\alpha$-dibromoenol ether (scan 1) into the enol-ether (scans 25). One checks that the enol ether is reversibly oxidized in two steps $\left(E_{p}=+0.04 \mathrm{~V}\right.$ and +0 . $20 \mathrm{~V}$ ). The self-inhibition of oxidation is possibly related to the thickness of the layer, so as the currents of the both steps decrease upon recurrent scans because of the radical cation coupling as well as of the reaction of the di-cation with moisture. This experiment permits to check that the deposit (in the course of its building) is not oxidized. The integration of the first scan between -0.2 and $+0.4 \mathrm{~V}$ permits to obtain a superficial concentration $\Gamma_{\text {enol }}=1.35 \times 10^{-8}$ mol cm$~^{-2}$. A fixed potential electrolysis of the $\alpha$-dibromoenol ether at $-0.6 \mathrm{~V}$ (no oxidation of the enol form) provides a very similar value $\left(1.6 \times 10^{-8} \mathrm{~mol} \mathrm{~cm}{ }^{-2}\right)$. Such experiments suggest the formation of a thick layer having the structure of a redox polymer (based on the reversible oxidation of $\{-\mathrm{O}$ (Pyrene $) \mathrm{C}=\mathrm{C}\}$ moiety). The motion of electrons inside the layer is slow, presumably being limited by the concomitant diffusion of $\mathrm{BF}_{4}^{-}$ions.

b) Another example is also displayed in Figure 2 (inset) by direct reduction of $\mathbf{1 b}$ at -0.8 $\mathrm{V}$ (amount of electricity: $3 \times 10^{-3} \mathrm{C} \mathrm{cm}^{-2}$ ). After sonication, a large reversible signal is revealed (apparently relative to one-electron exchange) with a progressive decay of the signal upon recurrent scans. The reduction step (first scan) is sharp and symmetrical. On the basis of oneelectron transitions, it allows to estimate the coverage as $\Gamma_{\text {enol }}=1.4 \times 10^{-8} \mathrm{~mol} \mathrm{~cm}^{-2}$.

\section{Conclusion}

The electrochemical reduction of $\omega$-bromomethylketoarenes in organic solvents of high dielectric permittivity (like propylene carbonate) in the presence of a supporting salt with 
iodide anion allows the primary deposition of alkenoxy radicals at carbon surface. Therefore, the coverage of enol ethers at electrode surfaces could be achieved and then offers new possibilities in the surface chemistry engineering. This reaction seems being totally unexpected if one forgets that radicals issued from the one electron scission of $\omega$ bromomethylketoarenes do react under two mesomeric forms, (i) the ketomethyl form and (ii) the alkenoxy form, the latter expected to be extremely reactive when compared to parent aryloxy radicals [10] towards unsaturated systems and especially towards GC known to contain large amounts of polyarenes. The high reactivity of alkenoxy radicals is certainly based on polymerization of the original deposit via successive radical additions (Scheme 1, reactions (6)). Thus, obtained redox polymers (as poly-enol ethers) correspond roughly to one hundred layer forms. Specifically, the reactivity of enol forms makes possible chemical modifications making this attached redox polymer highly versatile.

\section{References}

[1] D.G. Peters, in: H. Lund, O. Hammerich (Eds.), Organic Electrochemistry, M.M. Dekker, New York, Basel, 2001, p. 341.

[2] H. Lund, J. Simonet, J. Electroanal. Chem., 65 (1975) 205.

[3] A.A. Isse, A. De Guisty, A. Gennaro, Tetrahedron Lett., 47 (2006) 7735.

[4] F. Hui, J-M. Noël, P. Poizot, P. Hapiot, J. Simonet, Langmuir 27 (2011) 5119.

[5] J. Simonet, Electrochem. Comm., 13 (2011) 1417.

[6] V. Jouikov, J. Simonet, Chempluschem, 78 (2013) 70.

[7] D. Bélanger, J. Pinson, Chem. Soc. Rev. 40 (2011) 3995.

[8] V. Jouikov, J. Simonet, Electrochem. Comm., 27 (2013) 180.

[9] H. Schäfer, in [1], with quoted references on the electrochemistry of enol ethers.

[10] P. Neta, J. Grodkowsi, J. Phys. Chem. Ref. Data, 34 (2005) N 1.

\section{Figure Caption}

\section{Figure 1}

Voltammetry of 1c (concentration: $12.8 \mathrm{mmol} \mathrm{L}^{-1}$ ) in PC + TBAI_at solid electrodes. Scan rate: $50 \mathrm{mV} \mathrm{s}^{-1}$. Electrode surface area: $0.8 \mathrm{~mm}^{2}$. A) Response at a GC electrode. B) Response at a smooth gold electrode. C) Bromination of the electrode modified at $-0.9 \mathrm{~V}$ by fixed 
potential electrolysis (total amount of charge: $0.8 \times 10^{-3} \mathrm{C}$ ). Two scans. In the inset, principle of the bromination process and its reduction (re-generation of the enol ether) between -0.1 and $-2.0 \mathrm{~V}$.

\section{Figure 2}

Voltammetries of bromomethyl-ketopyrene 2 (concentration: $3.6 \mathrm{mmol} \mathrm{L}^{-1}$ ) in PC-EC (50:50 $\mathrm{v} / \mathrm{v})$ containing TBAI. San rate: $50 \mathrm{mV} \mathrm{s}^{-1}$. Surface area of used solid electrodes: $0.8 \mathrm{~mm}^{2}$.

A) Voltammetry at GC, Pt, and Pd electrodes. B) Initial reduction $\left(E_{R}=-0.6 \mathrm{~V}\right)$ of the deposit after bromination (scan 1) in $\mathrm{DMF} / \mathrm{TBABF}_{4}$. The regeneration of enol ether moieties (double reversible step) is followed by scans 2 to 5 .

B) For comparison, in the inset: oxidation (first three scans) of the layer obtained from $1 \mathrm{~b}$.

\section{Figure 3}

FTIR spectra of different layers obtained from bromo-ketoarenes at smooth GC. A, B and C: $\mathbf{3 , 2}$, and 1a, respectively. 